\title{
Ageing related events at nuclear power plants
}

\author{
Alexander Duchac \\ Nuclear Reactor Safety Assessment Unit, European Commission Joint Research Centre, Institute for Energy and Transport, Petten, \\ The Netherlands; Alexander.DUCHAC@ec.europa.eu
}

Received 26 July 2012; revised 24 August 2012; accepted 11 September 2012

\begin{abstract}
This paper presents main results of a comprehensive study performed by the European Clearinghouse on Operating Experience Feedback of NPP with the support of IRSN (Institut de Sûreté Nucléaire et de Radioprotection) and GRS (Gesellschaft für Anlagen und Reaktorsi-cherheit $\mathrm{mbH})$. Physical ageing mechanisms of structure, systems and components that eventually lead to ageing related systems and components failures at nuclear power plants were the main focus of this study. The analysis of ageing related events involved operating experience reported by NPP operators in France, Germany, USA and to the IAEA/NEA International Reporting system, on operating experience for the past 20 years (i.e. 1990-2009). A list of ageing related events was populated. Each ageing related event contained in the list was analyzed and results of analysis were summarized for each commodity group for which the ageing degradation appeared to be a dominant contributor or direct cause. The most common degradation mechanisms/ageing effects for each specific component/commodity group, their risk significance and consequences to the plant performance are described. This paper provides insights into ageing related operating experience as well as recommendations to deal with the physical ageing of nuclear power plant SSC important to safety.
\end{abstract}

Keywords: Ageing Management; Nuclear Power Plant; Ageing Degradation; Structures; Components; Nuclear Safety

\section{INTRODUCTION}

Ageing management at nuclear power plants should be proactive so that to timely detect the ageing degradations, and propose corrective actions to prevent structures, systems and components important to safety from ageing related faults. In order to mange the effect of ageing ef- fectively, there are various plant programmes available which provide guidance on ageing management of active and passive components.

Passive components are subject to ageing management review in order to identify ageing related degradations for given material, environment, stressors and operating loads. A comprehensive ageing management review is also required either for license renewal [1] or periodic safety review [2] of nuclear power plants.

Active components which perform their intended functions with moving parts or with a change in configuration are subject to preventive maintenance and replacement based on qualified life or specified time period; therefore the ageing management review is typically not performed. Instead, the plant maintenance programmes are established that should be able to detect timely the component degradation before it fails.

The plant maintenance and ageing management programmes aim at early detection of component ageing degradations; in an ideal case, there should not be many ageing related event reports. Despite the plant efforts to handle the ageing, the operating experience worldwide shows that there is still number of events reported that were caused by ageing related faults.

This paper presents the results of a comprehensive study [3] performed by the European Clearinghouse on Operating Experience Feedback of NPP with the support of IRSN (Institut de Sûreté Nucléaire et de Radioprotection) and GRS (Gesellschaft für Anlagen und Reaktorsicherheit $\mathrm{mbH}$ ). Physical ageing mechanisms of SSC were the main focus of this comprehensive study. Obsolescence, although it is important issue too, has currently not been included in this paper.

\section{IDENTIFICATION OF AGEING RELATED EVENTS}

A selection of ageing related events was performed through searching the IRSN, GRS, US NRC Licensees Event Reports and IAEA/NEA databases. Each database has its own reporting criteria, structure, and search tools. The identification of ageing related events was performed individually for each individual database. A time 
span of 20 years (1999-2009) offered several hundreds of events identified as ageing relevant for detailed evaluation. The analysis of operating experience (OE) also aimed to find answers on the following topics:

- What is the proportion of ageing related events from among all reported events;

- What are the affected components;

- What are the common degradation mechanisms;

- What are the consequences;

- What are the important lessons learned.

Total of 1125 events were identified from all databases as ageing related. This number appears to be small comparing to the large number of all reported events $(\sim 20,000)$; we have to assume however that not all ageing related events were identified (search by guide words may not always provide full result).

Proportion of individual component group in ageing related events is shown on Figure 1. As it can be seen, the passive mechanical components represent the biggest group among the ageing related events, active mechanical component group also represent non negligible contribution.

Most of the ageing related events of electrical and I\&C component group involved active components; only few passive components reported representing electrical and instrumentation cables. There were very few events reported on structures.

\section{RESULTS OF EVALUATION}

\subsection{General Findings}

Evaluation of ageing related operating experience identified several challenging issues and acknowledged important lessons learned. The ageing related events, in many cases, involved the equipment important to safety, challenged performance of SSC intended functions, lead to unanticipated plant transients such as a reactor trip or actuation of the plant engineered safety features.

The causes of ageing degradations associated with specific component group were determined mainly on

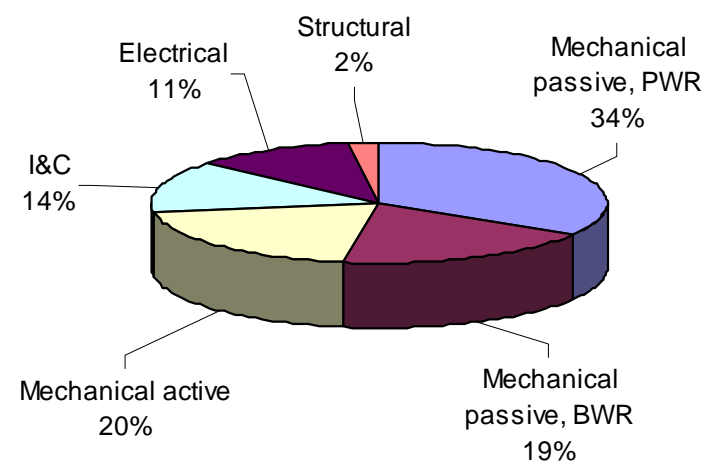

Figure 1. Component groups represented in ageing related events. passive components; it is a standard approach because the active components are subject to regular maintenance. The excessive wear was identified as dominant ageing degradation mechanism of the active components. It is important to mention that thermal ageing of lubricant or incorrect use of lubricant has significantly contributed to excessive wear.

The ageing degradation is typically latent and sometimes difficult to detect on time. The plant has typically set of specific programmes that help managing the ageing degradations of passive and active structure and component (SC). Although the main objective of these programmes is to timely detect any ageing degradation and provide set of preventive measures, in some cases SSC failures could not have been avoided.

As operating experience has shown, the ageing related events have potential to develop in common cause failures (CCF). For example, CCF associated with ageing of electrical equipment (cables, batteries, circuit breakers, capacitators, etc.) may result in failure of the entire component group. CCF failures generally develop slowly; in some cases it is quite difficult to detect them before the fault occurs.

The ageing can be effectively controlled if proper monitoring, maintenance, surveillance is in place, and certain equipment important to safety is subject to environmental qualification requirements. The environmental qualification generates testing or analytical evidence to ensure that equipment important to safety will meet performance requirements for the entire equipment design life, considering the anticipated in-service ageing.

\subsection{Component Specific Findings}

\subsubsection{Passive Mechanical Components}

Typical representatives of passive mechanical components identified in ageing related events were pipe works of reactor coolant system pressure boundary (main and auxiliary), steam generator tubes, steam generator collectors (VVER), steel vessels, heat exchangers tubes and flanges (particularly tubes of closed cooling water heat exchangers), valve and pump housings, core internals, such as core barrel/baffle bolts and fuel assembly alignment pins.

Dominant ageing degradation mechanisms were different types of corrosions and fatigues. For example, in case of reactor coolant pressure boundary, more than half of reported events were associated with corrosion and one third with fatigue degradations. The stress corrosion cracking (SCC) was identified as a major degradation mechanism at components made from austenitic steel.

\subsubsection{Active Mechanical Components}

Typical representatives of active mechanical compo- 
nents identified in ageing related events were motor and air operated valves, pumps, diesel engines and turbine driven pumps. It was particularly wear that was identified as frequent ageing effect in mechanical component moving parts, but also fatigue, corrosion, polymers/thermal ageing of various rubber and elastomer sealing materials used in mechanical components as seals, and gaskets. Replacement of affected mechanical parts of these components typically restores the original component functions and eliminates ageing degradations, if implemented on time.

A lubricant degradation due to thermal ageing was reported to cause excessive wear, sticking of mechanical parts, setpoint drift, or inoperability of the active mechanical components. This type of ageing degradations has a potential to develop to CCF. Three basic factors control lubricant degradation: The service time, the operating temperature, and the lubricant contamination. Time and temperature are directly related. The effective life of a lubricant can be extended when equipment is operated at moderate operating temperatures; contrary the effective time is reduced when equipment is operated at severe operating temperatures such as long-term engine operation at high loads or continues operation with highsulphur fuel.

\subsubsection{I\&C Components}

Most frequently reported I\&C components that failed due to ageing were electronic cards, relays, electrolytic capacitators, batteries, small power units, and switches. There were very few cases identified that involved passive I\&C components, i.e. instrumentation cables.

Typical ageing degradation mechanisms associated with I\&C components were loss of capacity, loss of insulation resistance, set point drift, and wear (relays). There were many cases that the ageing degradation mechanism was not identified, especially for electronic cards. It is believed that electrical failures (some may be ageing related) of certain small electronic components such as resistors, diodes, and electrolytic capacitators could be the cause.

Growing whiskers were identified to have caused inadvertent electrical conductive connections and lead to malfunctions or short circuits on the affected I\&C components. Tin whiskers are electrically conductive mono crystals which can grow out of tinnier surfaces even when they are coated. They reach lengths of several millimeters and in rare cases up to 10 millimeters. Considering a number of sensitive components installed in different systems important to safety, the increase rate of failure could impact the overall plant risk profile. A common cause failure of more than one train or multiple inter-system failures may also occur.

\subsubsection{Electrical Components}

This component group involved mainly active electrical components that failed due to ageing degradation. Typical representatives of this group are electrical circuit breakers (internal parts), electromotor (winding), transformer (bushing), large electrolytic capacitators in uninterruptible power supply modules (UPS), and relay (coils). Only few cases reported failures on electrical cables (passive component) that failed due to thermal ageing of insulation which eventually resulted in fracture of insulation.

The ageing degradation mechanisms associated with electrical component group were loss of insulation resistance, loss of capacity, and fracture toughness (el. cables). The "loss of insulation resistance" which was reported for electrical motor and transformer windings, electrical cables and relay coils was a dominant ageing degradation mechanism identified.

The loss of capacity was identified as dominant ageing degradation of large electrolytic capacitators which are used e.g. in UPS. Determination of electrolytic capacitator's life i.e., to find out when the capacitator loses its electrical properties and needs to be replaced, appears to be a challenging issue. Despite regular surveillance, there were cases reported that electrolytic capacitator failed shortly after inspection.

The excessive wear of internal (moving) parts of electrical circuit breakers was identified; the cause of excessive wear was the use of an inadequate lubricant, lubricant mixture, or lubricant (thermal) ageing. It shows how important the preventive maintenance of electrical circuit breakers is in order to provide for timely inspection as well as replacement of lubricant. This type of failure is typical CCF which could affect number of electrical circuit breakers in redundant trains.

For number of active electrical component failures the exact ageing degradation mechanism was not identified; with this regard the identification of ageing degradation mechanisms for active components, which are subject to replacement on a time specified interval, is not (always) required; it is easier to replace the faulted component on timely basis (unless it can run to failure) as required by corresponding preventive maintenance programme.

\section{LESSONS LEARNED}

\subsection{Generic Lessons Learned}

The operating experience form ageing related events shows the following lessons learned:

1) The evaluation of operating experience is an applicable and powerful tool to identify important safety issues and changes in the reliability of SSC due to ageing.

2) The operating experience shows that ageing related events are not dominant contributors among reported 
events; there are no increasing trends in frequency of ageing related events, neither in operating period, nor in reactor ages.

3) The proportion of ageing related events in the overall events reported depends also on event reporting criteria and practices may be different in Countries operating nuclear power plants. This fact mainly explains the existing differences in the estimated event frequencies, proportions of degradation mechanisms and contributing components.

4) In some cases, a different operating experience can be related to the same equipment but different design and material used. A typical example is the use of nickel base alloys in steam generator tubes which are susceptible to stress corrosion cracking. This led to a number of events that involved steam generator tubes in France, but not in Germany, where the steam generator tubes are made from different material.

The evaluation of ageing related operating experience solely based on information from the event reports was associated with the following difficulties:

- In many cases, additional information such as the design features of the affected structure and component, the prevailing operating loads and conditions would have been required complementary to those in the event reports so that to properly evaluate the SSC ageing behavior.

- Not all ageing related events appear to be reported; actually the reported events are just the "tip of the iceberg”. In particular, the maintenance data would have allowed for more precise analysis of the ageing, if available. This is evident particularly for I\&C components which are part of systems important to safety as well as supporting systems.

- The evaluation of operating experience seems to be insufficient especially for environmentally qualified equipment whose failures have to be avoided even under harsh environmental conditions at the end of their qualified life.

\subsection{Specific Lessons Learned Associated with Particular Component Group}

\subsubsection{Passive Mechanical Components (Pressure Pipes)}

Passive mechanical components can be characterized as highly reliable and in many cases "difficult to replace" components. It is supposed that once installed they should operate without replacement and renewal up to the end of their design lifetime. Consequently, there is no preventive maintenance performed, only performance monitoring and In-service Inspection (ISI). However, a failure of passive mechanical component could have an important consequence to the plant safety as it could lead to initiat- ing events, transients with large load reductions or loss of safety functions.

Various corrosion mechanism and fatigue contribute to events affecting passive mechanical components. In many cases, ageing related degradations were identified by non-destructive examinations, i.e. before component failures occurred. Nevertheless, leakages due to corrosion or fatigue occurred especially on small pressure pipes too.

A thermal stratification or mixing of hot and cold water can cause alternating loads with the result of thermal fatigue. If operating loads were not foreseen in the design, they can cause leakage up to a full break of the affected passive mechanical components such as pressure pipes. In fact, thermal fatigue has caused non-isolable primary coolant leakage in auxiliary pipes connected to the primary coolant in several plants worldwide.

A Trans Granular Stress Corrosion Cracking (TGSCC), which is caused when austenitic steel gets in contact with Chlorides, can develop to component failure, if not detected in time.

Components made from austenitic steel are generally not in the primary focus of recurrent ISI. This is true particularly for austenitic steel base metal of the pressurized pipe components, as most inspections are restricted to welds only. The chloride induced TGSCC was rarely detected in the course of the regular ISI programmes in the past. Most of the degradations were found either by the detection of leakage or in the course of unrelated maintenance activities, or due to supplementary inspections in response to information notices or operating experience feedback.

In order to minimize the chloride induced TGSCC it is important to avoid any contact of chlorides with austenitic steel components. The evaporation of coolant in partially filled stagnant systems may be sufficient to accumulate enough chlorides to induce TGSCC. Systems containing stagnant, two-phase coolant, where evaporation and concentration of chlorides might take place, should be identified in order to be considered in the ISI programme, as well as appropriate procedures to maintain water chemistry should be implemented in all plants.

\subsubsection{Active Mechanical Components}

The active components are repairable and, in general, replaceable in a time specific intervals, the event investigation process does not focus on identification and characterization of an ageing degradation mechanism.

A single failure of an active mechanical component in normal operation could have an impact to NPP performance, as it could lead to a transient. However, a safety impact of such types of failures is limited. A single failure of an active component in safety systems may also lead to loss of redundancy, but not to the loss of safety function. Safety significant events with the failure of 
active components are usually a combination of failures and/or additional factors, such as human errors or procedure deficiencies.

Thermal ageing of organic and polymer sub-components in air operated valves is a typical case of ageing degradation of component exposed to harsh environment. A development of ageing mechanism in combination with inappropriate maintenance practice has lead to failures of active components and impact the plant performance and safety.

The event reports do not always allow identifying what the problem was. Consequently, performing a timedependent analysis of component reliability data could be helpful. Corrective actions to eliminate the causes focused on optimization of preventive maintenance programmes, and replacement of sub-components or spare materials for upgraded ones.

\subsubsection{Electrical Components}

Ageing issues associated with electrical circuit breaker failures points on limitation of operating experience evaluation based just on event reports. In order to properly identify the ageing issues, more detailed data on component failures, operating times and stressors, as well as on applied maintenance strategy are needed.

A potential for common cause failures due to the ageing of electrical components is an important issue to consider. A risk of inter-system CCF could become a safety concern during the plant operation.

In some cases the improvements made in maintenance programmes were not sufficient to eliminate the root causes (especially, if they are related to the design of the components or sub-components). A replacement of worn out parts, or material substitution from which the part is made for a durable ones is a preferred solution.

\subsubsection{I\&C Components}

Ageing issues associated with failure of electronic cards together with electrolytic capacitators belongs to the most represented cases in I\&C commodity group. In particular, a whiskers formation on electronic boards was identified as a characteristic ageing mechanism affecting I\&C components. The whiskers formation can result in malfunctions or short circuits of electronic cards. Surveillance programmes should contain appropriate preventive inspection measures to identify whisker formation. In addition to improvement of surveillance and monitoring, the design upgrades of sensitive components which could eliminate whisker formation and consequent progression could be also considered as an effective solution.

A loss of capacity is a typical ageing degradation mechanism for electrolytic capacitators. Degradation of electrolytic capacitator is not always easy to identify.
Therefore, electrolytic capacitators shall be replaced on a specified time interval, given by the manufacturer.

Other degradation mechanisms observed in the evaluation of ageing related events were electrical failure, loss of insulation resistance, setpoint drift, and wear. Sometimes the degradation mechanism itself was not specified in the report.

In most cases, the ageing degradation was detected by components failure. Replacement of the failed component is the preferred corrective action.

A monitoring of reliability trends could be helpful to identify in time the ageing problem without "waiting” for a safety significant event occurrence.

\subsubsection{Structural Components}

Only few ageing events affecting structural components were identified.

Ageing degradation in structural components, such as concrete and steel reinforcement, is normally a comparably slow process. Therefore, careful visual inspection of structures at suitable intervals may be sufficient for most of these components. However, it is important that inappropriate inspection intervals may extend the period that degradation in a structural component can remain undetected, allowing further progression such that it may impact its operability.

\subsection{Risk Significance}

The evaluation of operating experience shows that ageing related faults and malfunctions mostly affected the plant process control systems, which belong to the plant normal operation system. This is more or less expected result because the number of equipment involved in these systems is much bigger, and safety classification and related qualification requirements are lower than for those safety related systems which resulted in the plant transients causing reactor trip or actuation of engineered safety systems, large power reduction and challenged a heat removal function (e.g. trip of reactor coolant pumps, and main feedwater pumps, turbine trips, turbine bypass malfunctions, set point drift of main steam safety valves, failure of emergency diesel generators, etc.).

It was observed that individual malfunction or failure of active mechanical, electrical, and I\&C components is acceptable in majority of cases because of redundant features included in the plant design. On the other hand, a potential to CCF due to ageing is an important issue to consider. A risk of inter-system CCF could become a safety concern during the plant operation.

It was also observed that number of events challenged component intended (safety) functions such as reactor coolant pressure boundary integrity, essential power supply, core cooling, reactor protection, and reactivity control (control rod drive malfunctions). 
Large number of ageing related degradations was detected during the plant walk downs, inspections and surveillance testing; this is a positive finding. The ageing related faults detected during the surveillance testing resulted in non-conformance with the plant Technical Specifications; in some cases this lead to a forced reactor shut down.

It appears that the plant equipment qualification programmes are generally effective; there were only few cases of ageing events identified that involved environmentally qualified SC.

\section{RECOMMENDATIONS}

Based on lessons learned from the ageing related events, the following recommendations can be made:

- The ageing degradations of passive mechanical, electrical and I\&C components should be managed by proper maintenance or ageing management programmes. Attributes as well as a format and content of generic ageing management programme can be found in [4] and [5]. These programmes should have a defined scope, monitoring methods to detect effects of ageing, acceptance criteria, and provisions for corrective actions as well as quality and documentation attributes. Application of ageing management programmes is a basis method to check the equipment fitness to service.

- The In-service inspection (ISI) programme is typical ageing management programme; it provides important source of data for ageing management allowing reassessment of SSC during the life time of the plant. The ISI results should be properly documented and regularly evaluated in order to augment the understanding of component behavior and load conditions of the components.

- Non-destructive test methods, equipment and personnel that are credited in ISI programmes must be qualified according to national standards, regulatory requirements, and international recommendations.

- The active mechanical, electrical and I\&C components which perform intended functions with moving parts or with a change in configuration should be subject to replacement based on qualified life or specified time period.

- The results of maintenance programmes for active mechanical components should be regularly evaluated and optimized when results show undesirable trends in equipment failures requiring corrective maintenance. The preventive maintenance programmes or introduction of condition based maintenance approach is highly recommended.

- The operating conditions of active and passive components should be further optimized in order to minimize the environmental stressors. In some cases, a protection against environmental stressors (e.g. thermal, radiation shielding) should be implemented.

- Certain electrical and I\&C components important to safety which are subject to environmental qualification requirements have a qualified life which is determined by the design, testing, analysis, and operating experience. The equipment qualification status should be preserved mainly through surveillance, maintenance, modification and replacement control, environment and equipment monitoring. The equipment shall be replaced before its qualified life expires, or it shall be re-qualified in accordance with special procedures.

- Ageing related operating experience associated with the plant SSC may significantly be improved if the reporting criteria contain specific “ageing” key words. Currently, most of the ageing related issues remain with the plant departments and industry.

- Results of R\&D should be regularly evaluated and implemented in order to better understand the ageing degradation mechanisms and contributing factors.

\section{CONCLUSIONS}

Ageing lessons learned generally provides important feedback to the plant programmes and practices that are intended to manage the ageing degradations of SSC at nuclear power plants.

The analysis of operating experience has shown that proportion of ageing related events is relatively low. However, their consequences, as well as their impact to the plant safety and reliability do not have to be negligible. A thorough investigation of ageing related operational events provides for valuable information and understanding what are the causes of ageing degradation. The event report itself however, does not always allow identifying what the (ageing) problem was. The maintenance data are required too. These are an important element for more precise analysis of the ageing phenomena. Provided that a representative set of data is available, performing a time-dependent analysis of component reliability data provides important insights on whether there are ageing related trends associated with SSC at nuclear power plants.

\section{REFERENCES}

[1] United States Nuclear Regulatory Commission (1995) Requirements for renewal of operating licenses for nuclear power plants. Office of Nuclear Reactor Regulation, Washington DC.

[2] International Atomic Energy Agency (2003) Periodic safety review of nuclear power plants. IAEA NS-G-2.10, Vienna.

[3] Duchac, A. (2011) Topical study on ageing related events. 
Topical Study, European Commission Joint Research Centre, Petten.

[4] International Atomic Energy Agency (2009) Ageing management for nuclear power plants. IAEA NS-G-2.12, Vi- enna.

[5] United States Nuclear Regulatory Commission (2010) Generic ageing lessons learned (GALL) report. Office of Nuclear Reactor Regulation, Washington DC. 